Research paper

\title{
Ileo-colonic delivery of conjugated bile acids improves glucose homeostasis via colonic GLP-1-producing enteroendocrine cells in human obesity and diabetes
}

\author{
Gerardo Calderon ${ }^{\mathrm{a}, 1}$, Alison McRae ${ }^{\mathrm{a}, 1}$, Juraj Rievaj ${ }^{\mathrm{c}, \mathrm{d}}$, Judith Davis ${ }^{\mathrm{a}}$, Inuk Zandvakilia, \\ Sara Linker-Nord ${ }^{\mathrm{a}}$, Duane Burton ${ }^{\mathrm{a}}$, Geoffrey Roberts ${ }^{\mathrm{d}}$, Frank Reimann ${ }^{\mathrm{c}}$, Bronislava Geduline \\ Adrian Vella ${ }^{\mathrm{b}}$, Nicholas F LaRusso ${ }^{\mathrm{a}}$, Michael Camilleri ${ }^{\mathrm{a}}$, Fiona M Gribble ${ }^{\mathrm{c}}$, Andres Acosta ${ }^{\mathrm{a}, *}$ \\ a Clinical Enteric Neuroscience Translational and Epidemiological Research (C.E.N.T.E.R.), Division of Gastroenterology and Hepatology, Mayo Clinic, Charlton 8- \\ 142, 200 First St. S.W., Rochester, MN 55905, United States \\ ${ }^{\mathrm{b}}$ Division of Endocrinology, Department of Medicine, Mayo Clinic, Rochester, MN, United States \\ ${ }^{\mathrm{c}}$ University of Cambridge, UK \\ ${ }^{\mathrm{d}}$ Current affiliation: Dosage Form Design \& Development, AstraZeneca Granta Park, Cambridge CB21 6GH, UK \\ e Satiogen Pharmaceuticals, San Diego, CA, United States
}

\section{A R T I C L E I N F O}

\section{Article History:}

Received 15 January 2020

Revised 26 March 2020

Accepted 3 April 2020

Available online $\mathrm{xxx}$

\begin{abstract}
A B S T R A C T
Background: The bile acid (BA) pathway plays a role in regulation of food intake and glucose metabolism, based mainly on findings in animal models. Our aim was to determine whether the BA pathway is altered and correctable in human obesity and diabetes.

Methods: We conducted 3 investigations: 1 ) BA receptor pathways were studied in $\mathrm{NCl}-\mathrm{H} 716$ enteroendocrine cell (EEC) line, whole human colonic mucosal tissue and in human colonic EEC isolated by Fluorescence-activated Cell Sorting (ex vivo) from endoscopically-obtained biopsies colon mucosa; 2) We characterized the BA pathway in 307 participants by measuring during fasting and postprandial levels of FGF19, $7 \alpha$ C4 and serum BA; 3) In a placebo-controlled, double-blind, randomised, 28-day trial, we studied the effect of ileo-colonic delivery of conjugated BAs (IC-CBAS) on glucose metabolism, incretins, and lipids, in participants with obesity and diabetes.

Findings: Human colonic GLP-1-producing EECs express TGR5, and upon treatment with bile acids in vitro, human EEC differentially expressed GLP-1 at the protein and mRNA level. In Ussing Chamber, GLP-1 release was stimulated by Taurocholic acid in either the apical or basolateral compartment. FGF19 was decreased in obesity and diabetes compared to controls. When compared to placebo, IC-CBAS significantly decreased postprandial glucose, fructosamine, fasting insulin, fasting LDL, and postprandial FGF19 and increased postprandial GLP-1 and C-peptide. Increase in faecal BA was associated with weight loss and with decreased fructosamine. Interpretations: In humans, BA signalling machinery is expressed in colonic EECs, deficient in obesity and diabetes, and when stimulated with IC-CBAS, improved glucose homeostasis. ClinicalTrials.gov number, NCT02871882, NCT02033876.

Funding: Research support and drug was provided by Satiogen Pharmaceuticals (San Diego, CA). AA, MC, and NFL report grants (AA- C-Sig P30DK84567, K23 DK114460; MC- NIH R01 DK67071; NFL- R01 DK057993) from the NIH. JR was supported by an Early Career Grant from Society for Endocrinology.
\end{abstract}

(c) 2020 The Authors. Published by Elsevier B.V. This is an open access article under the CC BY-NC-ND license. (http://creativecommons.org/licenses/by-nc-nd/4.0/)

\section{Introduction}

The enterohepatic circulation of bile acids is a complex pathway that regulates the synthesis, secretion, circulation, reabsorption and

\footnotetext{
* Corresponding author.

E-mail address: acosta.andres@mayo.edu (A. Acosta).

1 Both the authors are contributed equally to first authorship
}

excretion of bile acids (BAs) which are essential mainly for lipid digestion and absorption [1,2]. BAs are steroid-derived detergent molecules that form micelles to absorb cholesterol through the brush border membrane of the small intestine. The active BAs transport process in the distal ileum, mainly mediated by the apical $\mathrm{Na}^{+}$-dependent bile salt transporter (ASBT) [1], results in reuptake of $95 \%$ of BAs that enter the small intestine [3]; less than $5 \%$ of BAs are not reabsorbed in the small intestine, some of which undergo deconjugation 


\section{Research in context}

\section{Evidence before this study}

- The bile acid (BA) pathway plays a role in regulation of food intake and glucose metabolism, based mainly on findings in animal models.

- After bariatric surgery, bile acids may improve glucose metabolism by increasing bile acid concentrations in the distal gut.

- Whether the bile acid pathway is altered and correctable in human obesity and type 2 diabetes is unknown

\section{Added value of this study}

- Here we show that human colonic enteroendocrine GLP-1producing cells express TGR5 and FXR.

- In obesity with or without diabetes, serum FGF19 is decreased compared to healthy controls.

- When compared to placebo, delivery of capsules containing conjugated bile acids to the distal gut improves glucose homeostasis, incretins, LDL cholesterol and faecal bile acid levels without changing total cholesterol.

\section{Implications of all the available evidence}

- Our study further provides a mechanistic understanding of the effects of bile acids on the human pathophysiology of obesity and diabetes.

and dehydroxylation by colonic bacteria into secondary BAs prior to excretion in the stools. Passive colonic reabsorption of bile acids recovers some of the $5 \%$ of the bile salt pool that is not absorbed by the ileal active transport process [4]. In distal ileal enterocytes, reabsorbed BAs act as endogenous ligands for farnesoid $\mathrm{X}$ receptors (FXR) [5], stimulating the production of fibroblast growth factor-19 (FGF19), a marker of this bile acid pathway, which initiates negative feedback on the hepatocytes, to decrease the synthesis of BAs $[1,2]$.

BAs also act as signalling molecules through activation of the $G$ protein-coupled bile acid membrane receptor 1 (GPBAR1), known as TGR5 (Takeda G-protein coupled receptor 5) in small intestinal enteroendocrine cells (EECs) to cause metabolic effects $[1,6]$. In EECs, BAs activate TGR5, and induce CAMP/PKA signalling to trigger secretion of glucagon-like peptide-1 (GLP-1) [7], which, in turn, regulates energy metabolism [1,2]. However, it remains unclear whether human colonic EECs and epithelial cells (colonocytes) express bile acid transporters or the TGR5 receptor.

FGF19 has important biological effects. In rodents, FGF15 (Murine orthologue of FGF19) overexpressing transgenic mice have lower body weight and fat mass along with increased energy expenditure, despite increased food intake [8]. Also, systemic treatment with FGF19 improves glucose homeostasis and induces weight loss by stimulation of beta-klotho in the central nervous system [9]. However, more recent studies have shown that conditional knock-out mice with FXR deficiency in the intestine are protected against dietinduced obesity. Studies using intestinal specific FXR agonists or antagonists have shown contradictory effects [10-12]. Despite these intriguing observations, it remains unclear whether the bile acid pathway and its key components are altered in human obesity compared to healthy subjects.

It has been suggested that BAs play a role in the improvement of diabetes observed after bariatric surgery. Roux-en-Y gastric bypass (RYGB) doubles the concentration of serum BAs, and increases serum adiponectin and GLP-1 in humans [13,14]. In a rodent model of bariatric surgery, BAs delivered to the ileum induced weight loss and improved glucose homeostasis [15]. These results may be mediated by the BA receptor, TGR5 [15-18]. Stimulation of TGR5 results in a rapid increase in incretins, reduced appetite and improvement in insulin sensitivity [19,20]. Similar improvements in glucose homeostasis and increase in incretins have been seen with transgenic FXR/ FGF15 animal models after bariatric surgery [21,22]. These findings suggest that delivering bile acids to the distal ileum and colon may have positive effects on glucose metabolism. In the colon, BAs are deconjugated and then de-hydroxylated by colonic bacteria, mainly Bacteroides species, to secondary BAs (CA to DCA and CDCA to LCA). Secondary BA have the strongest affinity for TGR5 receptors ( $L C A>D-$ $\mathrm{CA}>\mathrm{CDCA}>\mathrm{CA})$ [2] and different affinities for FXR (CDCA $>\mathrm{DCA}=\mathrm{L}-$ $\mathrm{CA}>\mathrm{CA})$ or alternative $(\mathrm{CDCA}>\mathrm{CA}>\mathrm{DCA}>\mathrm{LCA})[23]$.

In this manuscript we proposed to answer three fundamental questions related to the bile acid pathway in human participants with obesity, with or without type 2 diabetes: 1 ) are bile acid receptors and downstream signalling molecules expressed in the human colon mucosa? 2) is the bile acid pathway altered in human obesity with or without type 2 diabetes?; and 3 ) does a composition-specific delivery of bile acids to the ileocolonic region improve glucose homeostasis in humans with obesity and type 2 diabetes?

\section{Methods}

\subsection{Cell culture experiments}

The Human L-cell line, NCI-H716, was obtained from the American Type Culture Collection and maintained at $37{ }^{\circ} \mathrm{C}, 5 \% \mathrm{CO}^{2}$ in suspension culture in T25 flasks (USA Scientific) containing RPMI media supplemented with $10 \%$ FBS, $100 \mathrm{IU} / \mathrm{ml}$ penicillin, and $100 \mu \mathrm{g} / \mathrm{ml}$ streptomycin $(1 \% \mathrm{p} / \mathrm{s})$. Forty-eight hours before experiments, cells were differentiated on matrigel-coated 6 -well plates $(400,000$ cells/ well) as previously described [24]. On the day of experiments, media was replaced with either PBS- $0.5 \%$ BSA $(2,4$, and $6 \mathrm{~h}$ incubations) or - low glucose DMEM (24 h experiments) with, or without test compounds: $1 \mathrm{mM}$ conjugated bile acids [CBAS, mainly conjugated bile acids (35\% TCA, 21\% GCA, 14\% TDCA, 10\% GDCA, 2\% TCDCA and 2\% GCDCA); and a small percentage of unconjugated bile acids (14\% CA, 2\% DCA and 2\% CDCA)] (Satiogen Pharmaceuticals, San Diego, CA), and $1 \mathrm{mM}$ chenodeoxycholic acid (Sigma). Cells were incubated for $2 \mathrm{~h}$ increments for duration of $6 \mathrm{~h}$, with media replacements, or for 24-hour duration. Cell viability was measured prior to experiments. Media and cells (collected in RNase-free PBS) were collected for ELISA and RNA analysis.

\subsection{Enzyme linked immunosorbent assays}

The active GLP-1 and FGF19 concentration of media supernatants was determined using commercially available ELISA kits, (EZGLPHS35 K, EMD Millipore; DF1800, R\&D Systems).

\section{3. $R T q P C R$}

Total RNA was extracted using the RNeasy Plus Micro Kit (Qiagen), reverse transcribed into cDNA using the AffinityScript QPCR cDNA Synthesis Kit (Agilent Technologies), and amplified by real-time quantitative PCR with gene-specific primers (Supplemental Table 1) using SYBR green (Bio-Rad) detection. Gene expression was calculated using the $2-\Delta \Delta \mathrm{Ct}$ method, and normalized to ACTB expression for each sample.

\subsection{Flow cytometry}

Single cell suspensions from human colonic biopsies were prepared for cell sorting as described [25]. Cell suspensions were stained with a fixable violet viability dye (1:1000, Life Technologies), followed by fixation and permeabilization using a Cytofix/Cytoperm kit (BD Biosciences). Cells were stained with an antibody specific for 
GLP-1 (ab23468, Abcam, 1:200, RRID:AB_470325), followed by an Alexa Fluor 488 conjugated donkey anti-mouse secondary (CA21202, ThermoFisher, 1:600). The viable fractions of GLP-1 positive and GLP-1 negative cells were sorted using a BDFACS Aria. Cell yield, composition, and FACS-plots were further assessed using the FlowJo software (FlowJo).

\subsection{Immunohistochemistry}

Human colonic biopsies were fixed in 10\% NBF for 6-hours (human), then embedded in paraffin. Five-micrometre sections were deparaffinised and rehydrated through a graded alcohol series, followed by antigen unmasking (Vector Laboratories). Tissue was permeabiliszed with $0.1 \%$ Triton X-100, and blocked with foetal bovine serum. FACS-isolated cells were attached to poly-L-lysine coated coverslips. Slides were incubated antibodies specific for GLP-1 (ab23468, Abcam, 1:200, RRID:AB_470325), FXR (PA540755, Invitrogen, 1:100, RRID:AB_2605921), TGR5 (ab72608, Abcam, 1:100, RRID: AB_2112165), or ASBT (sc-27493, Santa Cruz Biotechnology, 1:100, RRID:AB_2188364). For immunodetection, appropriate fluorochromeconjugated secondary antibodies were used to detect respective primary antibodies. A no primary antibody control was used for each antibody combination, where the tissue staining protocol omitted primary antibody incubation, and was only incubated with respective secondary antibodies and DAPI (supplemental figure $1 \mathrm{a}-\mathrm{c}$ ). Images were taken on a Confocal Microscope (LSM 780 Axio Observer), and analysed with the ZEN software (Zeiss).

\subsection{Ussing chamber methods}

Surgical specimens of fresh human colon were obtained from Tissue Bank at Addenbrooke's Hospital (Cambridge, UK) and used for experiments approved by the Research Ethics Committee. Ussing chamber experiments were performed with minor modifications as described previously [26].

\subsection{Methods for bile acid pathway characterization}

We studied a total of 307 participants with normal weight, overweight and obesity as part of a cohort of 509 people whose gastrointestinal traits have been reported elsewhere [27]. The participants with type 2 diabetes were selected prospectively for the conjugated BA and ursodeoxycholic acid experiments (described below). The study was approved by the Mayo Clinic Institutional Review Board, and all participants gave written informed consent. All co-authors had access to the study data and had reviewed and approved the final manuscript.

Participants underwent the blood collection at fasting and postprandial after a 300-calories breakfast. Serum was collected for measurement of serum BA by HPLC [28], FGF19 (described above) [28], and 7 Alpha-hydroxy-4-cholesten-3-one (7aC4) by HPLC-tandem mass-spectrometry [29]. Analysis using ANOVA.

\subsection{Methods for ileocolonic conjugated bile acids and ursodeoxycholic acid delivery}

\subsubsection{Randomisation and masking}

The placebo-controlled, double-blind, randomised controlled trial (NCT02871882) included randomisation and blinding. Twelve participants were randomised to each treatment arm, IC-CBAS or placebo, according to a computer-generated randomisation schedule by the study statistician's office and submitted to Mayo Clinic Research Pharmacy. Allocation was concealed. Experimenters were blind to group assignments, and the study blind was retained until all data had been recorded or analysed and locked in a "blinded database" by the statistician. The study was approved by the Mayo Clinic Institutional Review Board, and all participants gave written informed consent.

\subsubsection{Study design and details}

We performed a single centre, double-blind, placebo-controlled, parallel group, single dose randomised controlled trial of twice daily oral administration of delayed (ileocolonic) release conjugated BAs sodium extract (IC-CBAS, Satiogen Pharmaceuticals) $500 \mathrm{mg}$ or placebo administered for 28 days in patients with obesity and T2D (NCT02871882). The study was approved by the Mayo Clinic Institutional Review Board, and all participants gave written informed consent.

For complete details refer to supplemental section. Briefly, twelve participants completed a mixed meal tolerance test [30], gastric emptying by scintigraphy [27], appetite and satiation visual analogue scale [27], random stool sample [28] and blood samples were collected at fasting and postprandially [30] at baseline and 28-day of treatment. Participants were instructed to continue on the same diet and exercise routine during the entire therapeutic trial. The IC-CBAS is composed by conjugated bile acids (35\% TCA, 21\% GCA, 14\% TDCA, 10\% GDCA, 2\% TCDCA and GCDCA each) and a small percentage of unconjugated bile acids (14\% CA, 2\% DCA and 2\% CDCA); packaged in a methacrylated- enteric coating capsule to deliver compounds to the distal ileum and colon. The IC-CBAS dose of $500 \mathrm{mg}$ twice daily was selected based on previously completed single dose pharmacokinetic and pharmacodynamics studies using taurocholic acid via rectal enema [31].

\subsection{Statistical analysis}

The study was powered to detect a difference of $3247 \mathrm{mmol} / / 6 \mathrm{hr}$ in glucose area above basal (AAB) in 12 participants per group. Data are expressed as mean \pm SEM unless otherwise stated. The primary endpoint for analysis was area above basal (AAB) for glucose during treatment. Secondary endpoints were change in fasting glucose, weight, $\mathrm{AAB} / \mathrm{AUC}$ of glucose, insulin, c-peptide, GLP-1, and FGF19, gastric emptying, and faecal BA. The effects of IC-CBAS on each variable were assessed using analysis of covariance (ANCOVA) models incorporating the corresponding baseline value as a covariate. Parametric (student T-test) and non-parametric (Wilcoxon) analysis was done between the delta (change from baseline) in IC-CBAS compared to placebo. These analyses followed the intent-to-treat (ITT) paradigm, including all subjects randomised.

Similar methodology as described above was done to study the effect of Ileo-colonic Ursodeoxycholic Acid delivery (Actigal ${ }^{\circledR} 300 \mathrm{mg}$, Watson Pharmaceutical) (NCT02033876).

\subsection{Role of the funding source}

The funding source had no involvement in the study design, in collection, analysis, and interpretation of the data, in writing the report, or in the decision to submit the paper for publication. The corresponding author had full access to all the data in the study and takes responsibility for the integrity of the data, the accuracy of the data analysis, and the decision to submit for publication.

\section{Results}

\subsection{Expression and function of bile acid receptors in human colonic enteroendocrine cells}

Previously, FXR receptors have been reported in human ileal and colonic GLP-1 producing EEC [32], but evidence for expression of other important components of the BA pathway in GLP-1 producing EEC, such as TGR5, have been methodologically challenging to validate in human colon. We first sought to investigate the co-expression of GLP-1 with integral components of the bile acid pathway in human 
L- EECs. Thus, we analysed the protein expression of GLP-1 and TGR5 with standard immunofluorescence (IF) techniques using human colonic mucosal biopsies. We observed that in human colonic mucosa, GLP-1 positive cells also stain for TGR5 (Fig. 1a), which is again consistent with previous findings in rats [33]. Additionally, we interrogated the other BA receptor, FXR, which was previously shown to be expressed with GLP-1 [32]. Consistent with previous publications in mice and humans, we found that FXR was expressed in a population of GLP-1 positive cells in human colon, as well as surrounding colonocytes (supplemental Figure $2 \mathrm{a}, \mathrm{b}$ ).

To further validate the observation that human colonic EEC have functioning bile acid receptors, we stimulated the in vitro human colonic EEC line NCI-H716, with conjugated bile acids [CBAS, mainly $12 \alpha$-hydroxylated BA (cholic acid, deoxycholic acid and their conjugated forms), $1 \mathrm{mM}$ ), and observed a significant increase of GLP-1 secretion into the media at $2 \mathrm{~h}$ intervals over the course of $6 \mathrm{~h}$ following incubation, with nonsignificant effects on FGF19 secretion (Fig. 1b,c). Furthermore, in differentiated NCI-H716 cells, we compared effects of incubation with CBAS or chenodeoxycholic acid (CDCA) on mRNA expression of bile acid components GCG (GLP-1) (Fig. 1d) and FGF19 (Fig. 1e). After 24-hours, the mRNA expression of FGF19 was increased 5.5-fold after treatment with CDCA compared to treatment with CBAS $(p<0.001 ; t$-test) and 8 -fold compared to media-only controls $(p<0.001 ; t$-test $)(p<0.001$; ANOVA among three groups). The mRNA expression of GCG (GLP-1) was decreased 3-fold in response to CDCA treatment compared to CBAS $(P<0.05 ; t$-test $)$ and control $(P<0.01 ; t$-test $)$ in the human cell-line $(p<0.001$; ANOVA among three groups); consistent with the previously reported inhibitory effect of FXR activation on GCG expression in mice [32].

Given the possible limitations of studying EEC lineages, or using whole gut tissue which represent the heterogeneity of gut epithelial cell lineages, and also given the relative rarity of EECs in the colonic mucosa (estimated to be less than $1 \%$ of all epithelial cells), we extended these studies to FACS-isolated EECs obtained from human endoscopic biopsies, as was previously reported from surgical specimens [25,34]. We used a flow cytometric gating strategy (Fig. 2a, b) to identify EE L-cells using antibodies for GLP-1 (as a marker of Ltype EEC). The majority of the FACS-isolated, GLP-1 positive EECs expressed TGR5 (73\%) compared to the GLP-1 negative cells of which, 16\% expressed TGR5 (Fig. 2c, d).

To examine whether bile acids trigger GLP- 1 release from the human colon, we mounted human colonic tissue pieces in Ussing chambers. Taurodeoxycholic (TDCA) acid was applied to either the apical or basolateral compartment, and GLP-1 was measured over the following $90 \mathrm{~min}$ in the basolateral solution (Fig. 3a). GLP-1 release was stimulated by TDCA in either the apical or basolateral compartment, but the effect was significantly stronger when the bile acid was applied from the basolateral direction $(p<0.001 ; t$-test $)$. A similar experimental design applied to mouse colon revealed significant GLP-1 secretion when TDCA was applied basolaterally, but not apically (Fig. 3b). These findings are consistent with previous studies on rodent colon, and suggest that BA must be transported across the epithelium to access TGR5 located on the basolateral membrane $[26,33]$. Transport of TDCA could occur either following its deconjugation by microbiota, or by a transporter such as the apical sodium-coupled bile acid transporter, ASBT1. To examine whether ASBT1, which is believed to be predominantly located in the terminal ileum, is also found in human colon, we performed immunofluorescence staining of fixed tissue sections. ASBT1 was detectable in a proportion of epithelial cells but did not overlap with GLP-1 staining (Fig. 3c).

Overall, these data suggest that human colonic EEC co-expressed GLP-1 and TGR5, and that bile acids induce GLP-1 secretion in a human enteroendocrine cell line as well as human and mouse colonic tissue following their transport across the epithelium. Additionally, these suggest that conjugated bile acids stimulate the TGR5/GLP-1 pathway, while chenodeoxycholic acid triggers the FXR/FGF19 pathway and decreases the expression of GCG (GLP-1) These observations further demonstrate the differential binding affinities of BAs toward their target receptors, and further showcase the significance in considering this concept for clinical applications aimed at utilizing BA as potential modifiers of this pathway. Given the significant biological effects of bile acids in stimulating the incretin hormone GLP-1, it is relevant to assess whether this pathway is deficient in obesity and diabetes.

\subsection{Bile acid pathway deficiency in human obesity and diabetes}

Previous studies have described contradictory findings regarding the state of the bile acid pathway in obesity and diabetes; some studies described a lower serum BA levels in obesity and diabetes [13,14], while others describe insulin resistance in association with increased serum $12 \alpha$-hydroxylated BA elevated [35]; however, serum bile acid levels are not validated surrogates of the bile acid pathway and enterohepatic bile circulation. Validated surrogate biomarkers (such as FGF19, $7 \alpha$ C4 [biomarker of hepatocyte synthesis of bile acids] or 48hour faecal BA) have not yet been studied in obesity and diabetes compared to health. We measured the fasting and postprandial serum concentrations of FGF19, BA and $7 \alpha \mathrm{C} 4$ in 307 participants without diabetes [normal weight $(n=37)$, overweight $(n=89)$ or obesity $(n=181)$, age(SE) $37.4 \pm 0 \cdot 7 \mathrm{y}, 70 \%$ females, predominantly Caucasian] and in 48 obese participants with type 2 diabetes [age(SE) $53 \pm 0.7 y, 50 \%$ females, all Caucasian]. After adjusting for age and gender, weight group based on BMI is associated with differences in fasting FGF-19 (ANOVA among groups, $p<0.05$ ). Fasting FGF19 is reduced in obesity (median 89 [IQR $51-142.5] \mathrm{pg} / \mathrm{ml}$ ) compared to participants of normal weight (median 118 [IQR $62.9-172 \cdot 1] \mathrm{pg} / \mathrm{ml}$ ) or overweight when adjusted for age and gender (median 92.5 [IQR $63.8-144 \mathrm{Jg} / \mathrm{ml}$; difference in obesity compared to normal weight of $-26.5 \mathrm{pg} / \mathrm{ml}, 95 \%$ confidence interval $[\mathrm{CI}]-53$ to $-0.008, p<0 \cdot 01$ ) (Fig. 4a). The FGF19 level was similar in obese individuals with or without diabetes (Fig. $4 \mathrm{~b}$ ). There were no statistical differences in serum fasting $7 \alpha \mathrm{C} 4$ or $\mathrm{BA}$ among different weight groups (Fig. $4 \mathrm{c}$ and e) or diabetes status (Fig. $4 \mathrm{~d}$ and f). These results suggest that reduced serum FGF19 could be a marker for decreased BA stimulation of FXR receptors in obesity with or without diabetes; which improves after the bariatric surgery [35,36].

\subsection{Ileo-colonic delivery of conjugated bile acids improves glucose homeostasis}

The finding of TGR5 and FXR expression in human colonic EECs and the decreased levels of FGF19 in obesity demonstrates the therapeutic rationale and potential benefits of developing a mechanism to deliver bile acids into the terminal ileum-colon (where L-EECs are mainly located) to stimulate a TGR5-mediated GLP-1 release and FXR-mediated FGF19 expression. Thus, we encapsulated conjugated bile acids in a delayed-release, methacrylate-coated capsule [37-39] in order to assess the effect of ileo-colonic delivery of conjugated bile acids (IC-CBAS, Satiogen Pharmaceuticals, San Diego, CA) on BA pathways, incretins, glucose metabolism, and lipids., We completed a 28day, randomised, double-blind, parallel-group, placebo-controlled, proof of concept study in 23 participants with obesity and type 2 diabetes [Placebo: $58 \%$ female, Caucasian, age $( \pm$ SEM $) 54 \pm 2.8$ years, BMI $40.3 \pm 2.2 \mathrm{~kg} / \mathrm{m}^{2}$, and HbA1c $8.3 \pm 0.3 \%$; and IC-CBAS: $46 \%$ female, Caucasian, age $( \pm$ SEM $) 59 \pm 2.2$ years, BMI $36.7 \pm 1.5 \mathrm{~kg} / \mathrm{m}^{2}$, and HbA1c $8.9 \pm 0.4 \%$ ] (Supplemental figure 3 for study design and CONSORT chart, and supplemental Table 3a and 3b).

\subsubsection{Effect on blood glucose and fructosamine}

IC-CBAS treatment significantly decreased postprandial glucose

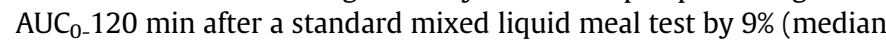
27763 [IQR 26398 - 30659][ $\mathrm{mg} / \mathrm{dl}]^{*} \mathrm{~min}$ vs 32989 [IQR 30,184 - 
a
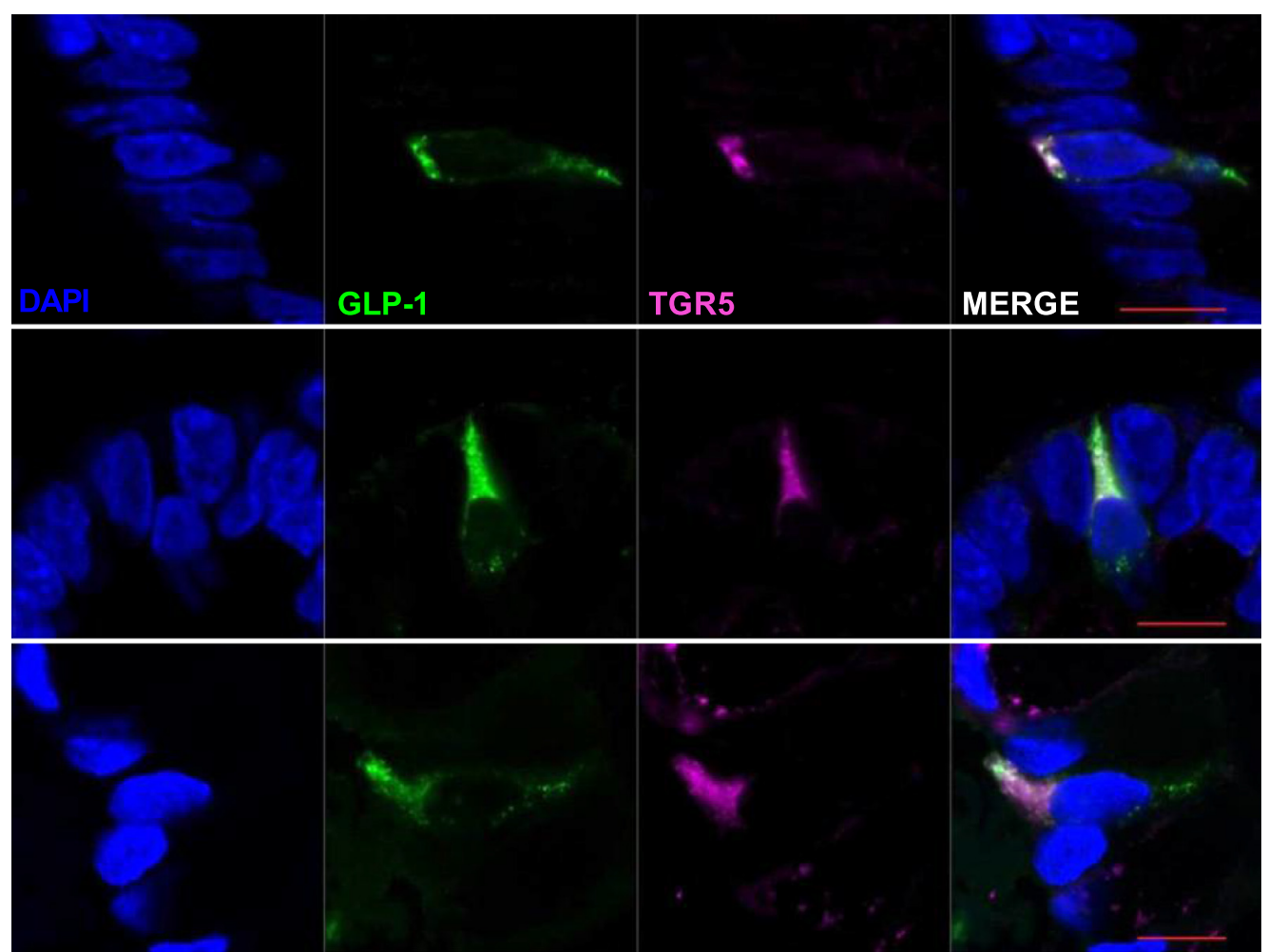

b

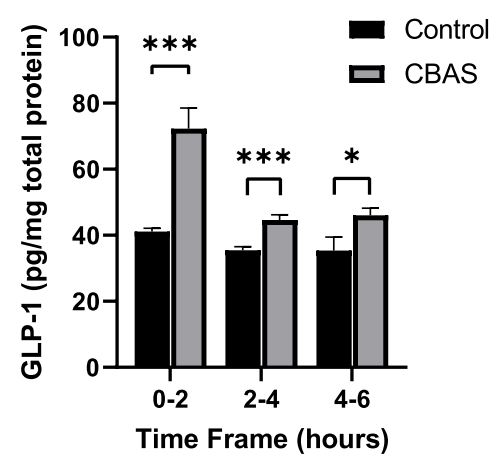

d

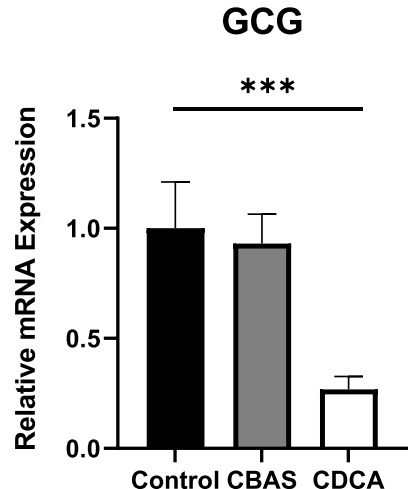

C

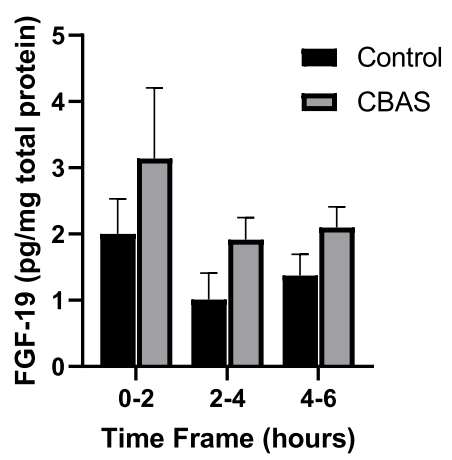

e

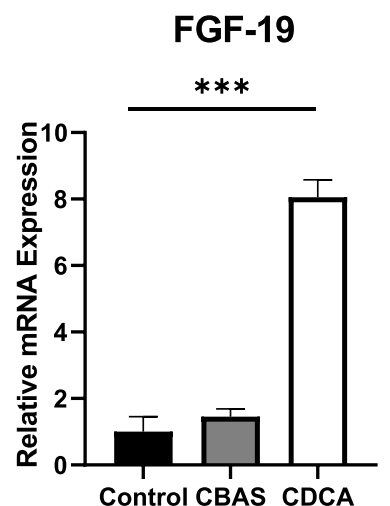

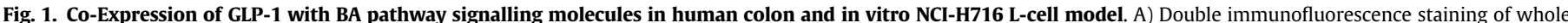

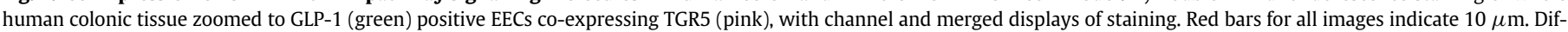

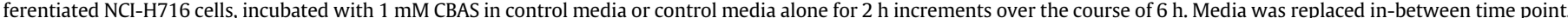

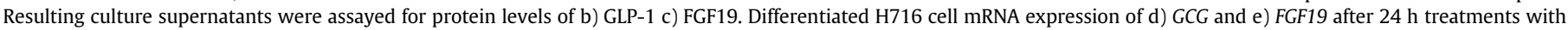

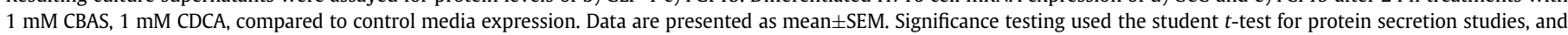
ANOVA for mRNA expression; ${ }^{*} p<0.05,{ }^{* *} p<0.01,{ }^{* * *} p<0.001$. 
a

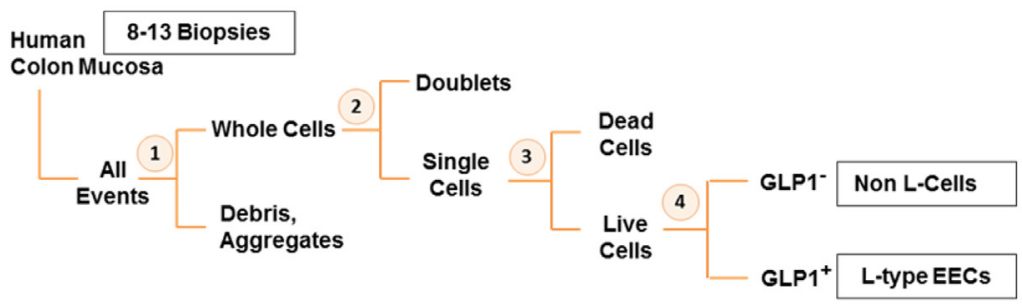

b
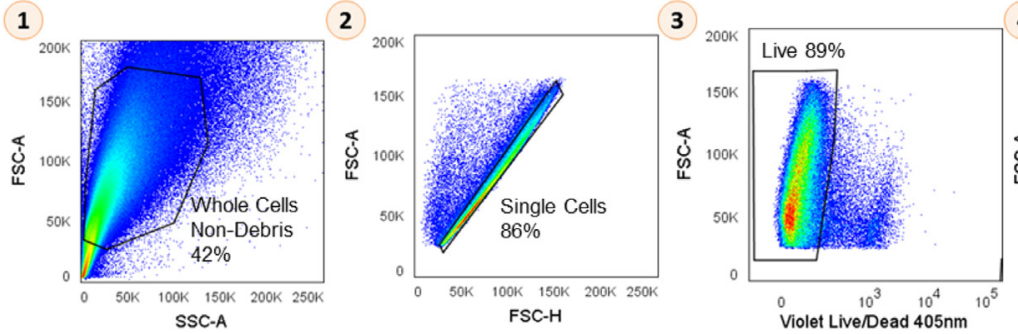

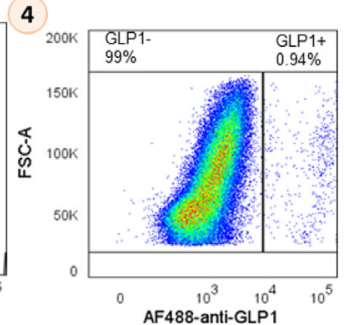

d

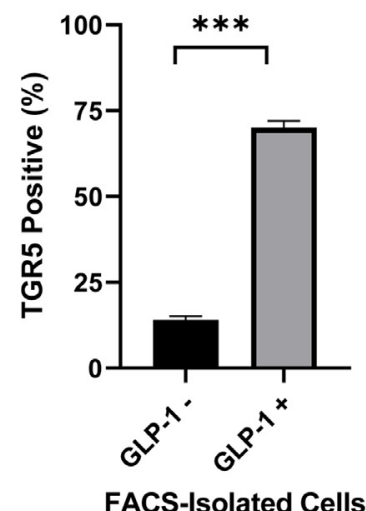

FACS-Isolated Cells
C

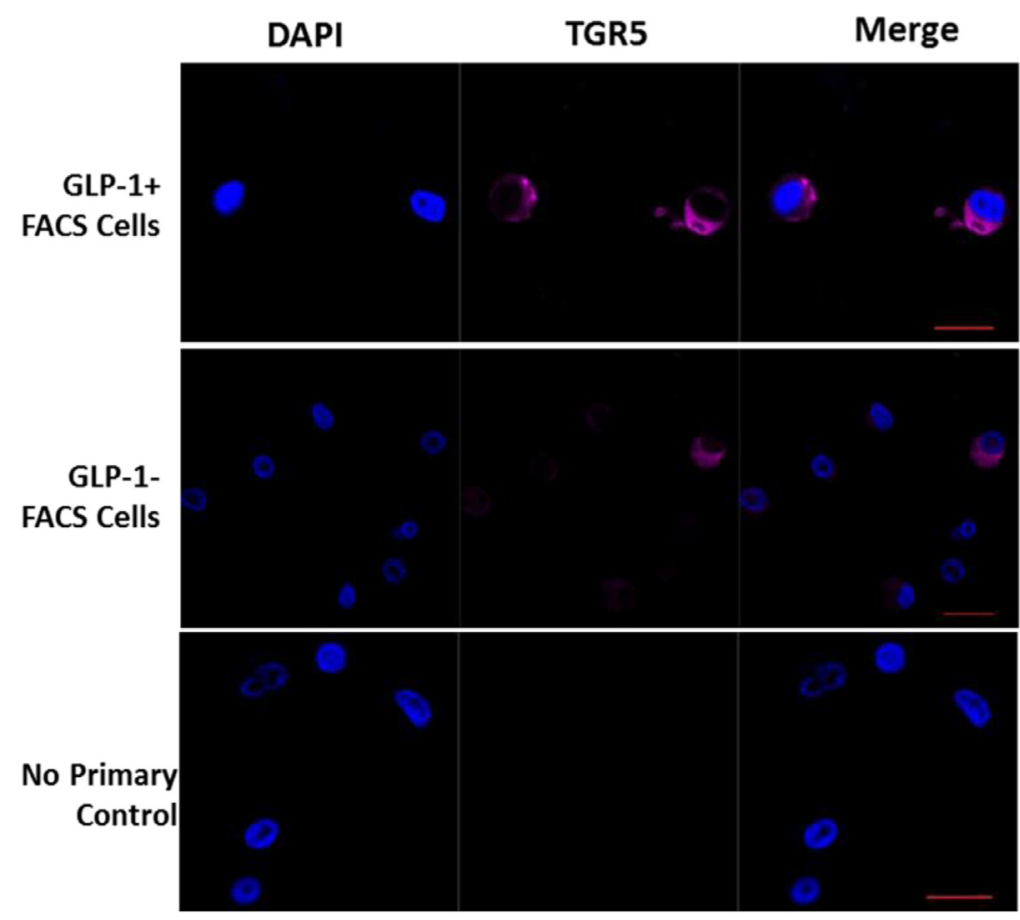

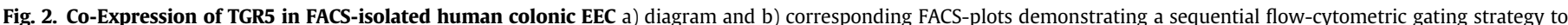

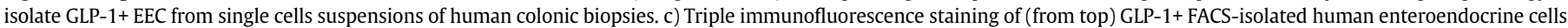

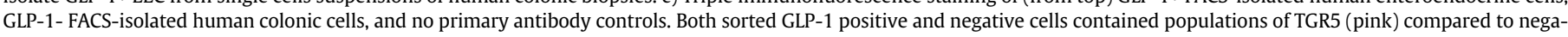

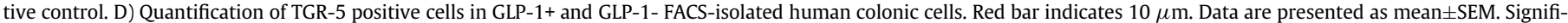
cance testing used the student $t$-test; ${ }^{*} p<0.05,{ }^{* *} p<0.01,{ }^{* * *} p<0.001$.

34723] [mg/dl] ${ }^{*}$ min; difference $-3165,95 \% \mathrm{CI},-6223$ to $862, p<0 \cdot 05$; Wilcoxon) (Fig. 5a, 5b, 5e and supplemental Table 3b). The postprandial glucose measured with $\mathrm{AAB}_{0-1} 120$ min after a standard mixed liquid meal test was not significantly different between placebo and ICCBAS (Fig. 5d). There was no significant difference in fasting glucose between IC-CBAS and placebo (Fig. 5c). To predict long-term glucose changes, we measured the validated-biomarker fructosamine [40], and found IC-CBAS significantly decreased fasting fructosamine compared to placebo (median $-20[\mathrm{IQR}-57-0] \mu \mathrm{mol} / \mathrm{L}$, vs placebo median -4 [IQR $-18-12] \mu \mathrm{mol} / \mathrm{L}$; difference $-16.95 \mathrm{umol} / \mathrm{L}, 95 \% \mathrm{CI}$
-39.4 to 5.4, $p<0.05$ Wilcoxon; Fig. 5f). There was no statistical difference in body weight (supplemental Table 3 ).

\subsubsection{Effect on GLP-1, insulin and C peptide}

The improvement in glucose and fructosamine was further interrogated by measuring GLP-1, insulin and c-peptide changes posttreatment. With 28-day treatment with IC-CBAS, there was significantly increased postprandial GLP-1 AUC $0-360$ min (IC-CBAS median 2330 [IQR 382 - 3927] vs Placebo: 46 [IQR - 3660 - 1318] [mg/dl] *min; difference $3223 \mathrm{mg} / \mathrm{dl}, 95 \%$ CI 1113 to 5332, $p<0.01$; Wilcoxon) (Fig. 5g, h, i). There was also a significant increase in postprandial c- 
a

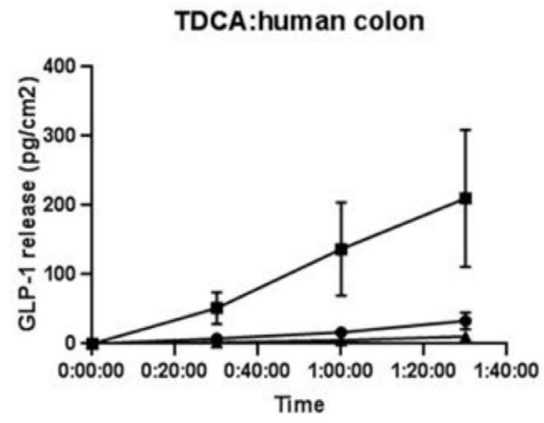

b

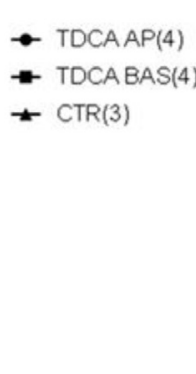

TDCA:mouse colon

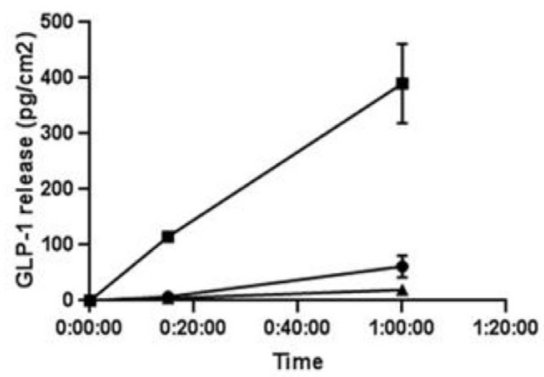

C
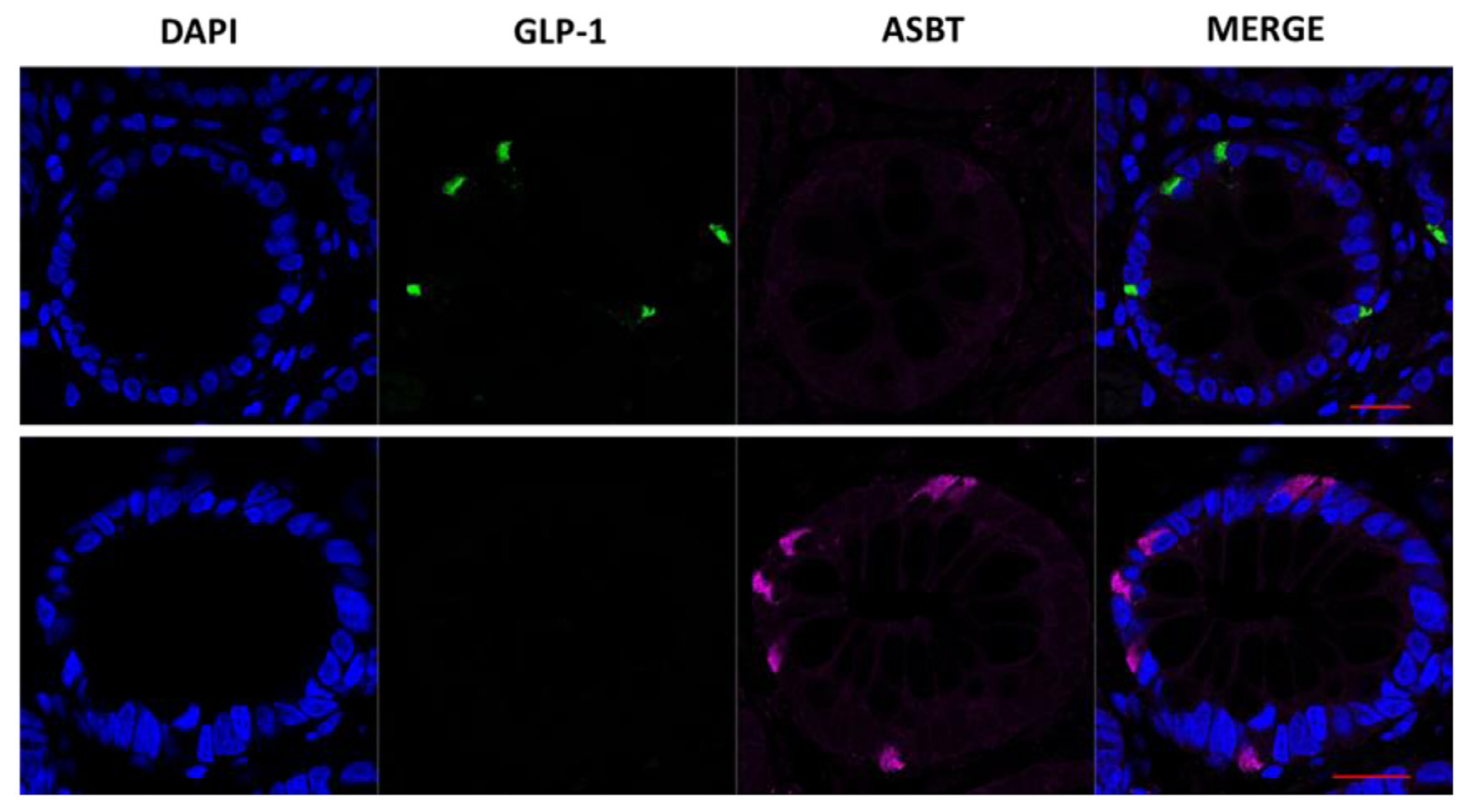

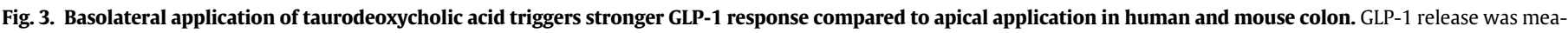

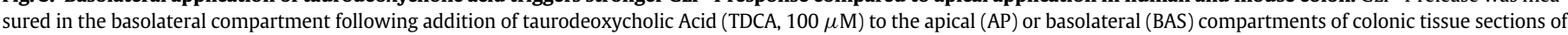

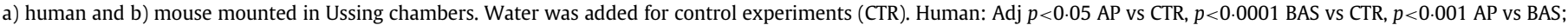

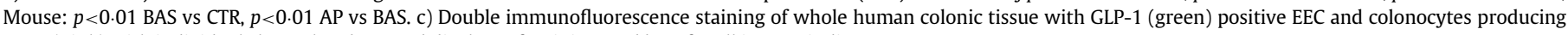
ASBT (pink) with individual channel and merged displays of staining. Red bars for all images indicate $20 \mu \mathrm{m}$.

peptide $\mathrm{AAB}_{0-3} 360 \mathrm{~min}$ (Difference $108 \mathrm{mg} / \mathrm{dl}, 95 \% \mathrm{CI} 34.5$ to 193.1 , $p<0.05$; Wilcoxon) (Fig. $5 \mathrm{j}$ ) and a significant decrease in fasting insulin (Fig. 5k) (difference $-5.3 \mathrm{md} / \mathrm{dl}, 95 \% \mathrm{Cl},-11.6$ to $1.1, p<0.05$; Wilcoxon). The postprandial insulin levels did not reach a statistically significant difference (Difference $1651 \mathrm{mg} / \mathrm{dl}, 95 \% \mathrm{CI}-283.2$ to 3583 , $p<0.1$ ) (Fig. 5l, supplemental Table 3).

\subsubsection{Effect on faecal bile acids, FGF19 and lipid profile}

Faecal BA concentration was increased in the IC-CBAS group compared to placebo (median 424 [IQR -57 - 944] vs -28 [IQR $-393-$ 222] $\mu \mathrm{mol} / \mathrm{L}$; difference $483.4,95 \%$ Cl 47.9 to $918.9, p<0.05$; ANCOVA, Fig. 6a, delta Fig. 6b). Percentage of primary bile acids were increased in the IC-CBAS group by $3.5 \%$ relative to placebo $(p<0.05$, Fig. 6c). IC-CBAS increased the faecal concentration of conjugated BA as expected (difference 296, 95\% CI 94.83 to 498.2, $p<0.05$; Wilcoxon; Fig. 6e). Faecal concentrations of the BAs, cholic acid (CA) and chenodeoxycholic acid (CDCA) were minimally altered with IC-CBAS treatment. Faecal deoxycholic acid (DCA), a secondary bile acid and product of bacterial deconjugation and dehydroxylation of $C A$, was increased in the IC-CBAS compared to placebo (difference $120 \mathrm{umol} / \mathrm{L}$, $95 \%$ CI 40.30 to 201.2, $p<0.01$, Wilcoxon; Fig. 6d). Also, CA was increased after the 28-days treatment (difference $28,9 \mathrm{umol} / \mathrm{L}, 95 \% \mathrm{Cl}$
-8 to $65.8, p<0.01$; Wilcoxon). There was no significant difference in fasting serum BA, 7aC4, FGF19, and total cholesterol with IC-CBAS compared to placebo (Fig. 6f, g, h, i).

Fasting LDL significantly decreased in the IC-CBAS group compared to placebo (median -4.6 [IQR $-14--3$ ] vs.3 [IQR $0-8] \mathrm{mg} /$ $\mathrm{dl}$; (difference $-11 \mathrm{mg} / \mathrm{dl}, 95 \% \mathrm{Cl} 4.3$ to $17.6, p<0.01$, Wilcoxon; Fig. $6 \mathrm{j}$ ). Increased total faecal bile acids with IC-CBAS treatment were associated with a greater weight loss $\left(R^{2}=-0.36, p<0.05\right.$; linear regression) and a decrease in fructosamine levels $\left(R^{2}=-0.61, p<0.05\right.$; linear regression) (Figs. 6k, l).

\subsubsection{Effect of IC-CBAS on gastric motility, weight loss, and stool diaries}

There was no difference in gastric emptying measured by scintigraphy, daily stool diaries, medication compliance, and no side effects.

\subsection{Ileo-colonic delivery of ursodeoxycholic acid on glucose homeostasis}

To test whether the effect of IC-CBAS was bile acid specific, we completed a similar trial, in a similar population with ileo-colonic ursodeoxycholic acid (IC-UDCA), a secondary bile acid with weak affinity for TGR5 and FXR. (See more details, study design and 
a

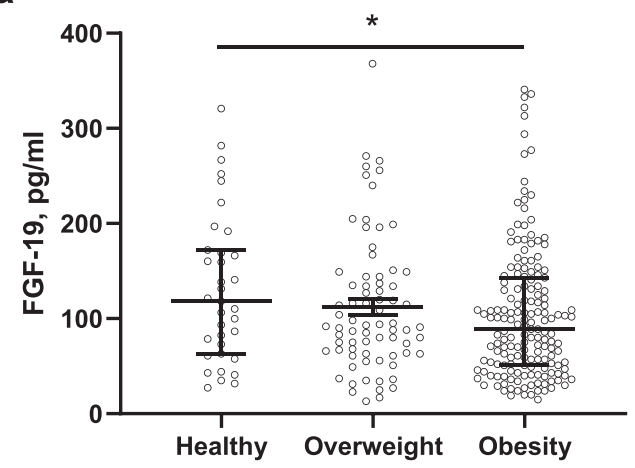

C

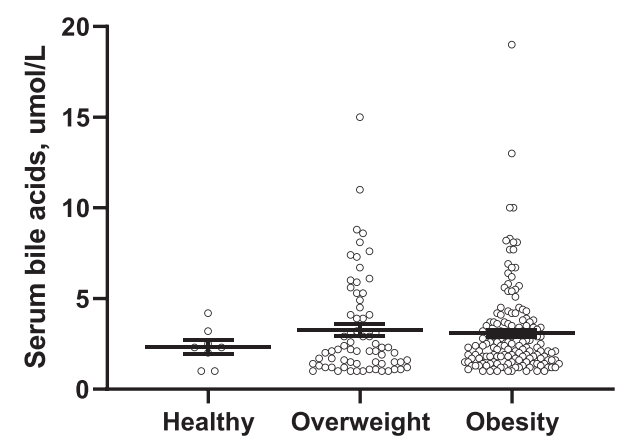

e

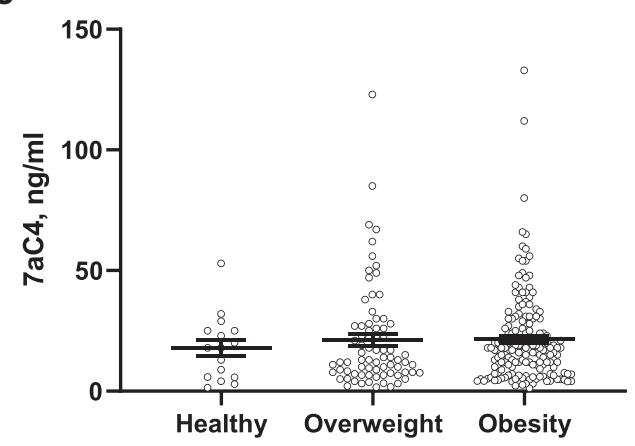

b

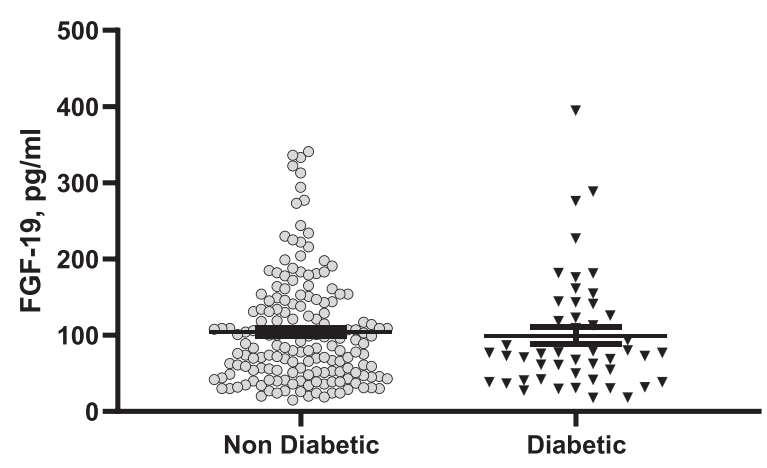

d

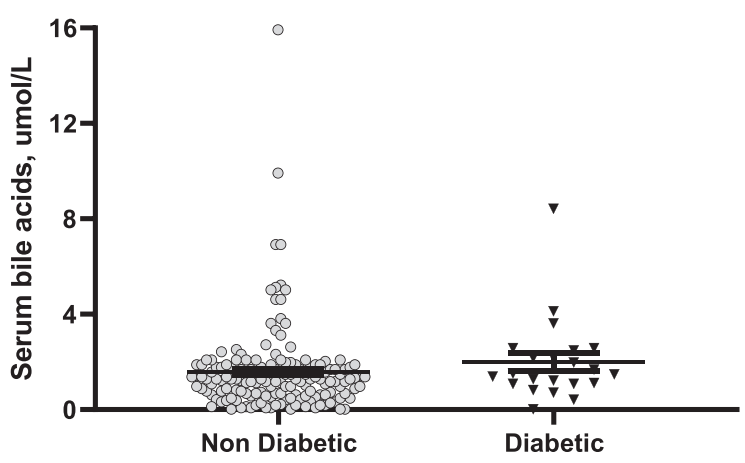

f

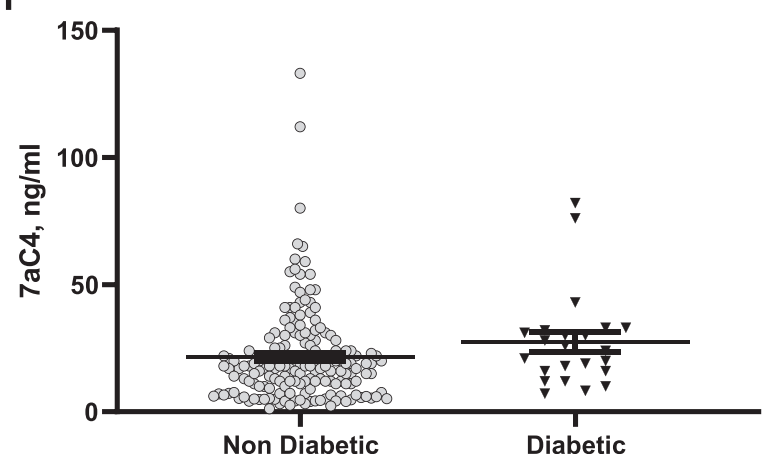

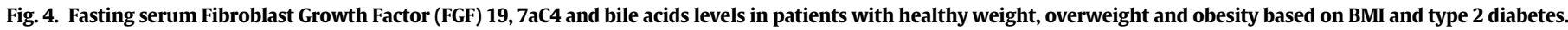

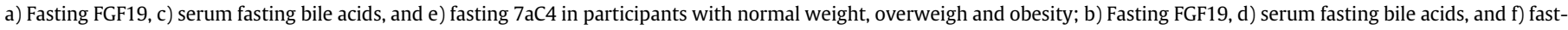
ing $7 \mathrm{aC} 4$ in participants with obesity with or without diabetes, Data are represented as median [IQR]. ANOVA* $p<0.05$.

complete results in supplemental section). The IC-UDCA treatment group showed no significant difference in glucose, insulin, C-peptide, body weight, bowel movements or gastric motility. However, ICUDCA significantly reduced fasting FGF19 when compared to placebo (IC-UDCA: 52 IQR [33.8-100]; placebo: 90.2 IQR [56.8-143.5]mg/dl ANCOVA $p<0.01$ ) (Supplemental Table 4).

\section{Discussion}

Bile acids are signalling molecules playing major roles in glucose metabolism and energy intake [41]. Despite significant progress, mainly from transgenic animal models and studies of bariatric surgery, our understanding of the bile acid pathway in human obesity and diabetes remains incomplete and controversial. Here, we aimed to further clarify the role of the bile acid pathway in the development and maintenance of human obesity and diabetes, and its potential for therapeutic modulation by bile acid supplementation. This study was predominantly focused on humans since rodents have discernible differences in the bile acid pathways [42,43].

Our findings support the hypothesis that human colonic EEC express TGR5 and FXR, as previously reported in the ileum of mice and humans [32,33], and we showed that both pathways previously described in GLUTag cells [26,32] are also present in NCI-H716, an enteroendocrine cell line originating from human colon cancer [44] and routinely used as a surrogate for EECs [45]. Using a novel technique to sort enteroendocrine L-cells from human colonic mucosal biopsies, we showed staining for TGR5 and FXR in GLP-1 positive cells. Expression of TGR5 is enriched in GLP-1 positive EEC of the colon. Furthermore, in an ex-vivo model of human colonic mucosal function, GLP-1 release was stimulated by TDCA with the effect significantly stronger when the bile acid was 
a

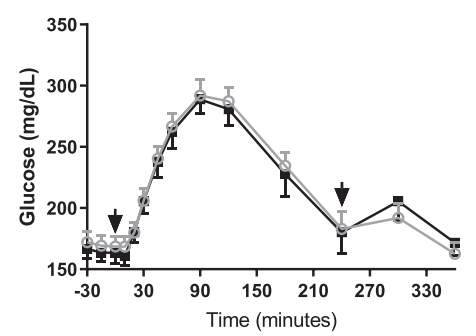

d

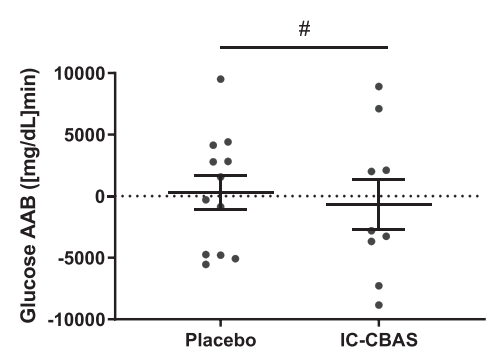

g

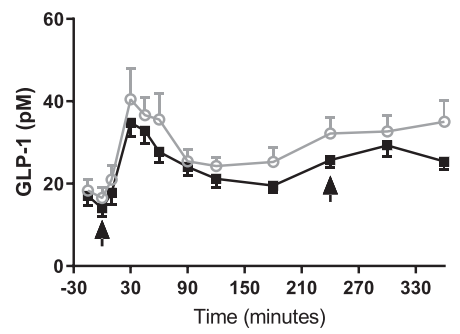

j

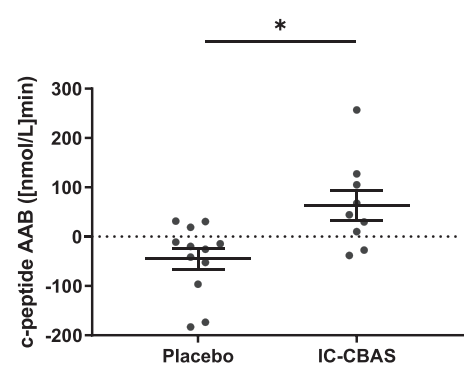

b

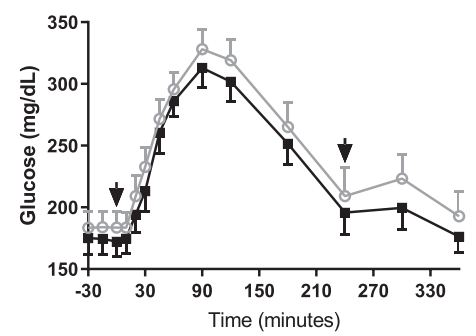

e

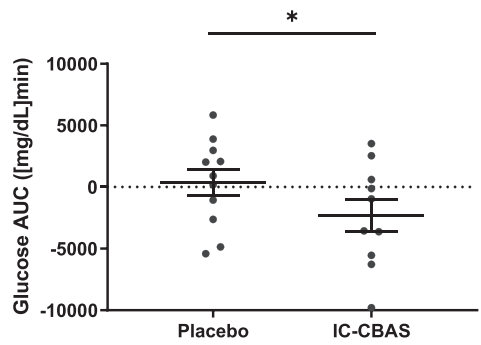

h

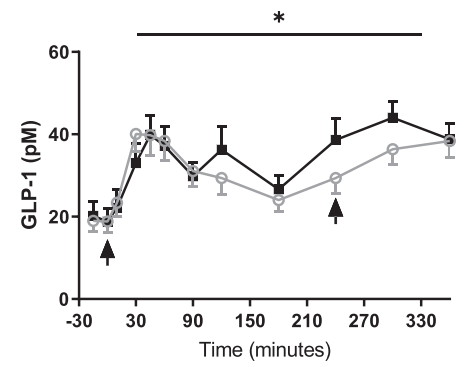

k

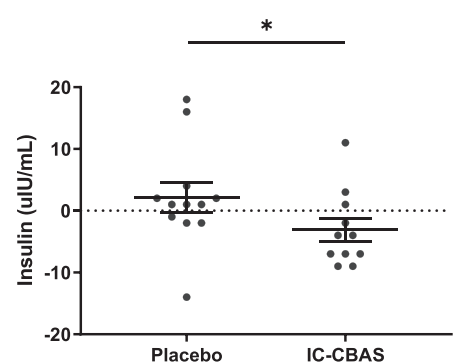

C

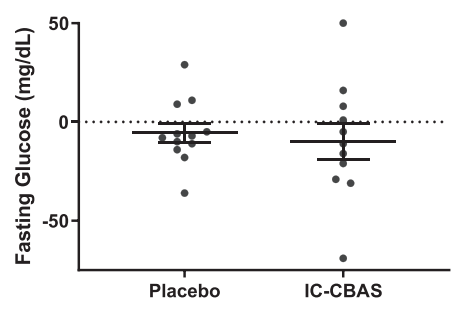

f

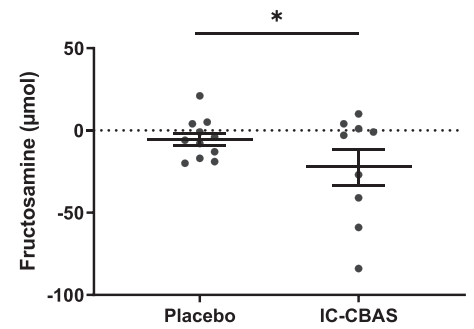

i

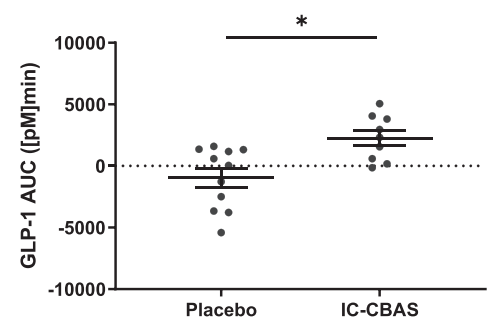

I

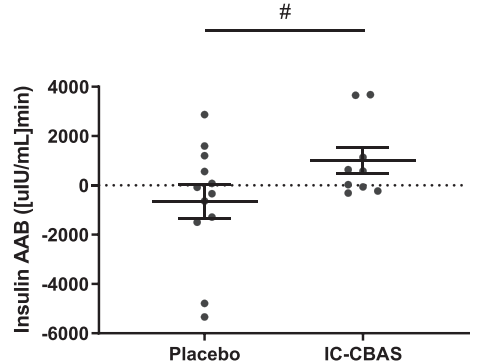

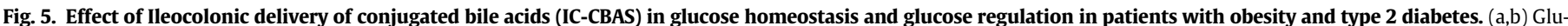

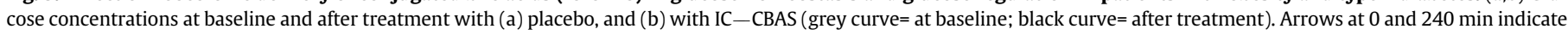

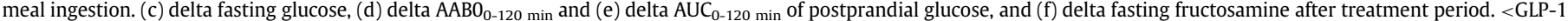

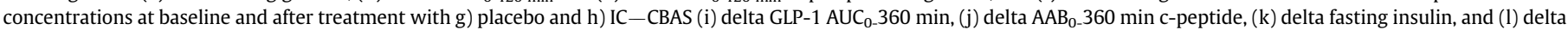
$\mathrm{AAB}_{0-} 120$ min insulin after treatment period. Data are presented as mean \pm SEM. Wilcoxon test treatment vs. placebo: ${ }^{*} p<0 \cdot 1 .{ }^{*} p<0 \cdot 05,{ }^{* *} p<0 \cdot 01$.

applied from the basolateral direction. These findings are consistent with previous publications in mice and rat colon and suggest the importance of the colon for bile acids sensing [33].
In comparing the bile acid pathway in obesity and health, we found that fasting FGF19 was decreased in obesity with or without diabetes when compared to healthy controls. FGF19 is a well- 
a

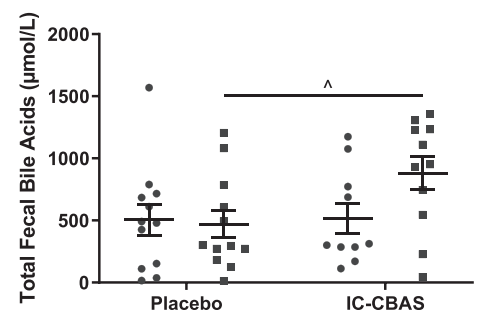

d

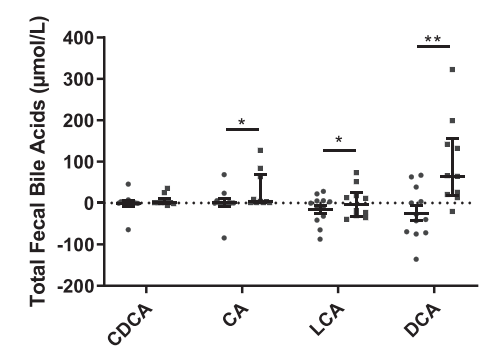

g

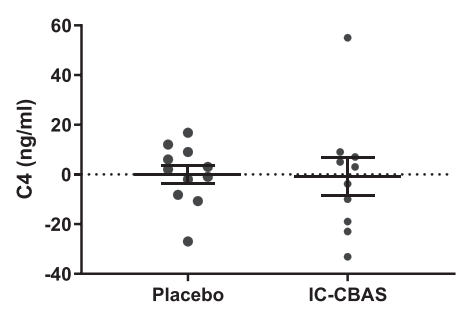

j

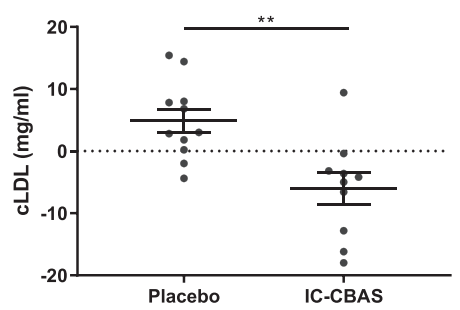

b

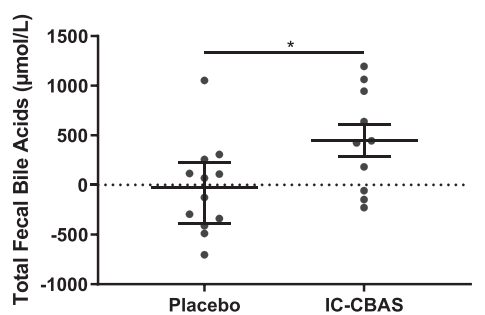

e

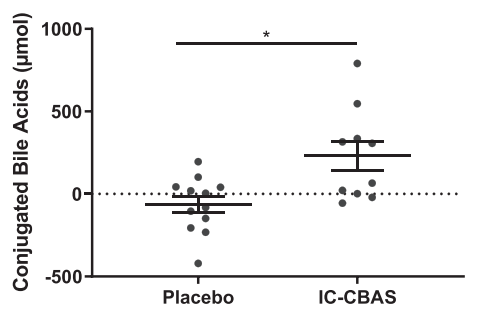

h

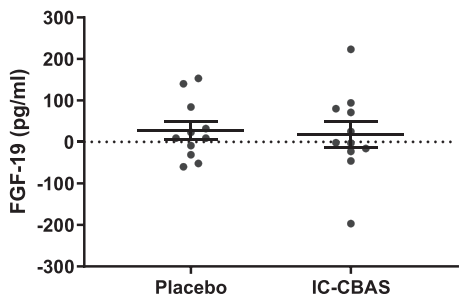

C

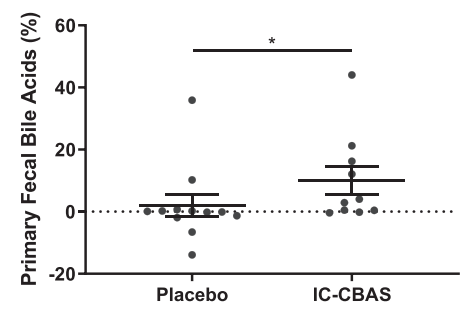

f

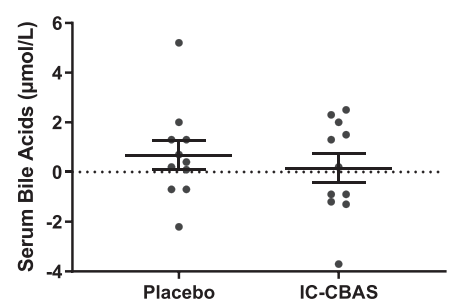

i

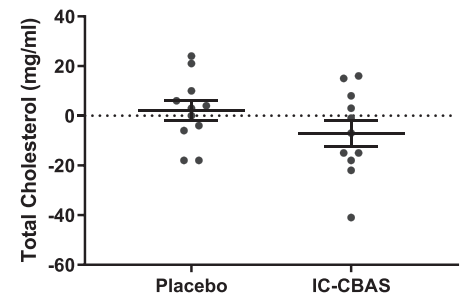

m
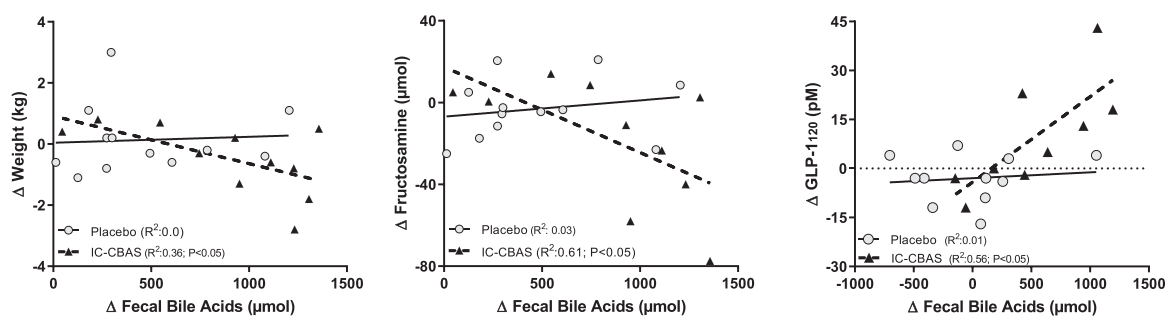

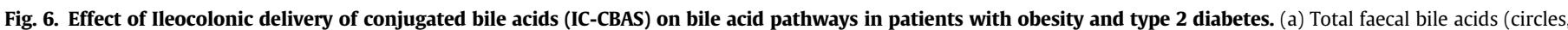

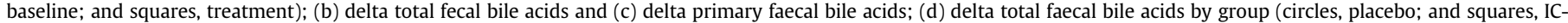

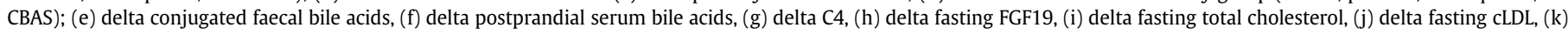

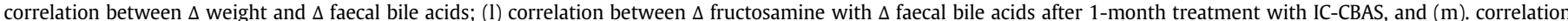

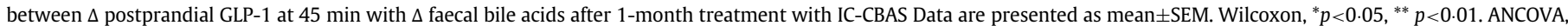
${ }^{\wedge} p<0 \cdot 05$, (Figs. $\mathrm{a}-\mathrm{j}$ ).

established biomarker for the bile acid pathway, enterohepatic circulation and bile acid-related diseases [46-48], as it largely arises from the distal ileum where its expression is dependent on bile acid absorption and FXR activation. Given that there is minimal absorption of bile acids before they reach terminal ileum, these results could suggest a reduction of luminal bile acids, or a reduction in FXR expression or activity in ileal enterocytes in obesity. This is consistent with previous findings from smaller sample-size studies showing decreased serum BAs $[13,17,18,49-51]$ in obesity compared to lean subjects. Although we did not detect differences in serum bile acid concentrations in our large sample size study, it is important to note that we reported fasting values while the previously mentioned studies reported postprandial changes which would be more likely to influence FGF19 production in the terminal ileum. Moreover, the reduced effect of endogenous BA on the synthesis of FGF19 in obesity is concordant with reports that in obesity there are lower levels of GLP-1 [52,53] and PYY [27,54], which are released after EEC stimulation by BAs and other stimuli [55].

We delivered conjugated bile acids to the ileo-colonic region as a proof of concept study to investigate whether this would result in improvements in blood glucose homeostasis. Thus, the consumption of oral capsules of IC-CBAS twice daily for 28 days in participants with obesity and diabetes exerted a small lowering of post-prandial glucose concentrations, improved LDL cholesterol, and altered faecal bile acid levels; but IC-CBAS did not correct the FGF19 deficiency. The results of this medium-term study with an oral ileo-colonic (delayed released) capsule are similar to those from two acute, short term studies involving acute infusion of intrarectal taurocholic acid (TCA) 
[31] and intrajejunal infusion of TCA [19]. However, both previous studies used higher concentrations of TCA, which could have resulted in side effects or bile acid toxicity if administered in longer-term trials [2]; in contrast, our participants receiving IC-CBAS reported no side effects of IC-CBAS $500 \mathrm{mg}$ twice daily.

The IC-CBAS administered in our study consisted of conjugated BAs when delivered into the intestinal tract, but they were efficiently altered by bacterial deconjugation and dehydroxylation as evidenced by the percentages of different bile acids recovered in the stools. A number of previous studies have concluded that the stimulation of GLP-1 secretion by bile acids involves TGR5 receptors located on the basolateral surface of L-cells; this would suggest that bile acid absorption is an obligatory step prior to cell activation. In the small intestine, the predominant bile acid absorptive pathway involves apical ASBT, and likely occurs predominantly through enterocytes, thereby building up high local bile acid concentrations in the basolateral space surrounding L-cells [26]. Colonocytes, by contrast, have relatively low expression of ASBT, and rely on alternative pathways for absorption of unconjugated bile acids. Recent results also suggest the existence of an ASBT-independent pathway for conjugated bile acid uptake in the rodent colon, linked to the secretion of GLP-1 [33]. The responsiveness of colonic GLP-1 release is bile acid-specific, reflecting the specificity of TGR5, since the study with ileo-colonic delivery of ursodeoxycholic acid $(3 \alpha, 7 \beta$ cholanoic acid, which is a $7 \beta$ epimer of chenodeoxycholic acid) showed no benefit on glucose homeostasis. Participants treated with IC-CBAS had a significant increase in postprandial GLP-1 which is likely related to the time when the oral capsule reached the ileum and the colon (approximately $4 \mathrm{~h}$ post capsule ingestion) and consistent with small bowel transit of a tablet [56]. The release of GLP-1 was likely responsible for the observed increase in secretion of c-peptide (and non-statistically significant increase of insulin), which may explain the improvement of glucose and fructosamine. Further studies are needed to assess whether $>3$ months treatment with IC-CBAS would improve haemoglobin A1c. The observed improvement in fructosamine is comparable to previous studies with FDA-approved anti-diabetic medications [57-59]. Additionally, this proof of concept study used a single dose (500 mg twice daily); a dose titration study should be pursued in future to identify the appropriate dose to maximize benefits on glucose control.

Interestingly, IC-CBAS increased faecal bile acids without altering serum bile acids or FGF19; in addition, it significantly decreased LDL cholesterol. These observations are important as treatment with bile acids has been previously associated with dyslipidaemia by increasing lipid absorption [2]. On the other hand, delivery of bile acids into the ileo-colonic region likely bypasses the lipid digestion effect of bile acids, whilst allowing them still to modulate glucose metabolism. A similar pattern of improved glycaemic control is seen when bile acid sequestrants are used to treat dyslipidaemia, diabetes and bile acid diarrhoea [30]. The mechanism of action of bile acid binding on glucose homeostasis may differ from that of the IC-CBAS, since bile acid binders do not increase the postprandial GLP-1 concentration in some studies [30]; one potential reason is because they prevent bile acids from reaching the basolateral membrane surface of L-cells [60]. However, studies in rodents have shown an increase in postprandial GLP-1 concentration with bile acid binders [61,62].

IC-CBAS were not able to restore the FGF19 deficiency seen in obese humans. Our findings support the importance of considering the bile-acid specific composition profile needed to stimulate FXR/ FGF19 compared with TGR5/GLP-1. Thus, CDCA induced expression of FGF19 but inhibited the expression of GLP-1, consistent with an active FXR pathway in NCI-H716 [32], whereas the bile acid mixture used in our human study had the opposite effect, likely reflecting the lack of CDCA or other strong FXR ligands in the bile acid mix in the IC-CBAS. Furthermore, our findings of IC-UDCA reducing FGF-19 supports the recent evidence seen in rodents, in which conjugated
(Taurine or glycine) UDCA behaves as an FXR antagonist [63]. It is also possible that the bile acids delivered by capsules in humans and by infusion in rats did not raise bile acid concentrations to high levels in the terminal ileum, which is believed to be the major site of FXRdependent FGF15/19 production.

In conclusion, our results demonstrate that FXR and TGR5 are coexpressed with GLP-1 in human colonic enteroendocrine L cells. Furthermore, FGF19 is reduced in obesity, suggesting a defect in bile acid signalling. In an attempt to correct this, bile acid delivery selectively to the human ileum and colon by ingestion of capsules twice daily resulted in a small but significant improvement in glucose homeostasis, although it did not restore FGF19 levels. Our study further provides a mechanistic understanding of the effects of bile acids on the human pathophysiology of obesity and diabetes.

\section{Acknowledgements}

We thank volunteers, the nurses and staff of the Mayo Clinic Clinical Research Unit for nursing support and the care of patients. Research support and drug was provided by Satiogen Pharmaceuticals (San Diego, CA). The study was conducted in the clinical research unit (supported by Mayo Clinic centre for Clinical and Translational Science [CCaTS] grant UL1-TR000135). AA, MC, and NFL report grants (AA- C-Sig P30DK84567, K23 DK114460; MC- NIH R01 DK67071; NFL- R01 DK057993) from the NIH. JR was supported by an Early Career Grant from Society for Endocrinology.

\section{Funding sources}

The funding source had no involvement in the study design, in collection, analysis, and interpretation of the data, in writing the report, or in the decision to submit the paper for publication. The corresponding author had full access to all the data in the study and takes responsibility for the integrity of the data, the accuracy of the data analysis, and the decision to submit for publication.

\section{Declaration of Competing Interest}

AA is a stockholder in Gila Therapeutics, Phenomix Sciences and Lipiquester; he serves as a consultant for Rhythm Pharmaceuticals, General Mills, Gila Therapeutics. MC is a stockholder in Phenomix Sciences and serves as a consultant to Takeda, Allergan, Rhythm, Salix, Arena, Enterin. BG is a stockholder in Satiogen Pharmaceuticals. All other authors report no relevant financial or personal conflicts of interest.

\section{Data sharing}

Data collected for the study, including individual deidentified participant data, as well as study protocol, and informed consent will be available to interested parties with publication, after signing of a data access agreement. Data may be requested by contacting Dr. Andres Acosta M.D, Ph.D., at acosta.andres@mayo.edu.

\section{Supplementary materials}

Supplementary material associated with this article can be found in the online version at doi:10.1016/j.ebiom.2020.102759.

\section{References}

[1] Camilleri M, Gores GJ. Therapeutic targeting of bile acids. Am J Physiol Gastrointest Liver Physiol 2015;309(4):G209-15.

[2] Chiang JY. Bile acid metabolism and signaling. Compr Physiol 2013:3(3):1191-212.

[3] Simmonds WJ, Hofmann AF, Theodor E. Absorption of cholesterol from a micellar solution: intestinal perfusion studies in man. J Clin Invest 1967;46(5):874-90.

[4] Mekhjian HS, Phillips SF, Hofmann AF. Colonic absorption of unconjugated bile acids: perfusion studies in man. Dig Dis Sci 1979;24(7):545-50. 
[5] Parks DJ, Blanchard SG, Bledsoe RK, Chandra G, Consler TG, Kliewer SA, et al. Bile acids: natural ligands for an orphan nuclear receptor. Science 1999;284 (5418):1365-8.

[6] Symonds EL, Peiris M, Page AJ, Chia B, Dogra H, Masding A, et al. Mechanisms of activation of mouse and human enteroendocrine cells by nutrients. Gut 2015;64 (4):618-26.

[7] Thomas C, Gioiello A, Noriega L, Strehle A, Oury J, Rizzo G, et al. TGR5-mediated bile acid sensing controls glucose homeostasis. Cell Metab 2009;10(3):167-77.

[8] Tomlinson E, Fu L, John L, Hultgren B, Huang X, Renz M, et al. Transgenic mice expressing human fibroblast growth factor-19 display increased metabolic rate and decreased adiposity. Endocrinology 2002;143(5):1741-7.

[9] Lan T, Morgan DA, Rahmouni K, Sonoda J, Fu X, Burgess SC, et al. FGF19, FGF21, and an FGFR1/beta-Klotho-Activating antibody act on the nervous system to regulate body weight and glycemia. Cell Metab 2017;26(5):709-18 e3.

[10] Watanabe M, Horai Y, Houten SM, Morimoto K, Sugizaki T, Arita E, et al. Lowering bile acid pool size with a synthetic farnesoid x receptor (FXR) agonist induces obesity and diabetes through reduced energy expenditure. J Biol Chem 2011;286 (30):26913-20

[11] Li F, Jiang CT, Krausz KW, Li YF, Albert I, Hao HP, et al. Microbiome remodelling leads to inhibition of intestinal farnesoid $\mathrm{X}$ receptor signalling and decreased obesity. Nat Commun 2013;4:2384.

[12] Fang S, Suh JM, Reilly SM, Yu E, Osborn O, Lackey D, et al. Intestinal FXR agonism promotes adipose tissue browning and reduces obesity and insulin resistance. Nat Med 2015;21(2):159-65.

[13] Ahmad N, Pfalzer A, Kaplan L. Roux-en-Y gastric bypass normalizes the blunted postprandial bile acid excursion associated with obesity. Int J Obes 2005:1553-9 2013.

[14] Dutia R, Embrey M, O'Brien S, Haeusler RA, Agenor KK, Homel P, et al. Temporal changes in bile acid levels and 12alpha-hydroxylation after Roux-En-Y gastric bypass surgery in type 2 diabetes. Int J Obes 2016;40(3):554

[15] Kohli R, Setchell K, Kirby M, Myronovych A, Ryan K, Ibrahim S, et al. A surgical model in male obese rats uncovers protective effects of bile acids post-bariatric surgery. Endocrinology 2013

[16] Kohli R., Kirby M., Setchell K.J.Intestinal adaptation after ileal interposition surgery increases bile acid recycling and protects against obesity-related comorbidities2010.

[17] Kohli R, Bradley D, Setchell K, Eagon J, Abumrad N, Klein S. Weight loss induced by roux-en-y gastric bypass but not laparoscopic adjustable gastric banding increases circulating bile acids. J Clin Endocrinol Metab 2013;98(4):12.

[18] Pournaras DJ, Glicksman C, Vincent RP, Kuganolipava S, Alaghband-Zadeh J, Mahon $\mathrm{D}$, et al. The role of bile after roux-en-y gastric bypass in promoting weight loss and improving glycaemic control. Endocrinology 2012;153(8):3613-9.

[19] Wu T, Bound M, Standfield S, Jones K, Horowitz M, Rayner C. Effects of taurocholic acid on glycemic, glucagon-like peptide-1, and insulin responses to small intestinal glucose infusion in healthy humans. J Clin Endocrinol Metab 2013:98(4):22.

[20] Kars M, Yang L, Gregor M, Mohammed B, Pietka T, Finck B, et al. Tauroursodeoxycholic acid may improve liver and muscle but not adipose tissue insulin sensitivity in obese men and women. Diabetes 2010;59(8):1899-905.

[21] Ryan KK, Tremaroli V, Clemmensen C, Kovatcheva-Datchary P, Myronovych A, Karns R, et al. FXR is a molecular target for the effects of vertical sleeve gastrectomy. Nature 2014;509(7499):183-8.

[22] Bozadjieva N, Heppner KM, Seeley RJ. Targeting fxr and FGF19 to treat metabolic diseases-lessons learned from bariatric surgery. Diabetes 2018;67(9):1720-8.

[23] Zhang JH, Nolan JD, Kennie SL, Johnston IM, Dew T, Dixon PH, et al. Potent stimulation of fibroblast growth factor 19 expression in the human ileum by bile acids. Am J Physiol Gastrointest Liver Physiol 2013;304(10):G940-8.

[24] de Bruine AP, Dinjens WN, van der Linden EP, Pijls MM, Moerkerk PT, Bosman FT. Extracellular matrix components induce endocrine differentiation in vitro in $\mathrm{NCI}$ H716 cells. Am J Pathol 1993;142(3):773-82.

[25] Habib AM, Richards P, Cairns LS, Rogers GJ, Bannon CA, Parker HE, et al. Overlap of endocrine hormone expression in the mouse intestine revealed by transcriptional profiling and flow cytometry. Endocrinology 2012;153(7):3054-65.

[26] Brighton CA, Rievaj J, Kuhre RE, Glass LL, Schoonjans K, Holst JJ, et al. Bile acids trigger GLP-1 release predominantly by accessing basolaterally located g proteincoupled bile acid receptors. Endocrinology 2015;156(11):3961-70.

[27] Acosta A, Camilleri M, Shin A, Vazquez-Roque MI, Iturrino J, Burton D, et al. Quantitative gastrointestinal and psychological traits associated with obesity and response to weight-loss therapy. Gastroenterology 2015;148(3):537-5460000.

[28] Vijayvargiya P, Busciglio I, Burton D, Donato L, Lueke A, Camilleri M. Bile acid deficiency in a subgroup of patients with irritable bowel syndrome with constipation based on biomarkers in serum and fecal samples. Clin Gastroenterol Hepatol 2018;16(4):522-7.

[29] Donato LJ, Lueke A, Kenyon SM, Meeusen JW, Camilleri M. Description of analytical method and clinical utility of measuring serum 7-alpha-hydroxy-4-cholesten3-one (7aC4) by mass spectrometry. Clin Biochem 2018;52:106-11.

[30] Smushkin G, Sathananthan M, Piccinini F, Dalla Man C, Law J, Cobelli C, et al. The effect of a bile acid sequestrant on glucose metabolism in subjects with type 2 diabetes. Diabetes 2013;62(4):1094-101.

[31] Adrian TE, Gariballa S, Parekh KA, Thomas SA, Saadi H, Al Kaabi J, et al. Rectal taurocholate increases L cell and insulin secretion, and decreases blood glucose and food intake in obese type 2 diabetic volunteers. Diabetologia 2012;55(9):2343-7.

[32] Trabelsi M-SS, Daoudi M, Prawitt J, Ducastel S, Touche V, Sayin SI, et al. Farnesoid $\mathrm{X}$ receptor inhibits glucagon-like peptide-1 production by enteroendocrine I cells. Nat Commun 2015;6:7629.

[33] Christiansen CB, Trammell SAJ, Wewer Albrechtsen NJ, Schoonjans K, Albrechtsen $\mathrm{R}$, Gillum MP, et al. Bile acids drive colonic secretion of glucagon-like-peptide 1 and peptide-YY in rodents. Am J Physiol Gastrointest Liver Physiol 2019;316(5): G574-G84.

[34] Habib AM, Richards P, Rogers GJ, Reimann F, Gribble FM. Co-localisation and secretion of glucagon-like peptide 1 and peptide YY from primary cultured human L cells. Diabetologia 2013;56(6):1413-6.

[35] Haeusler RA, Astiarraga B, Camastra S, Accili D, Ferrannini E. Human insulin resistance is associated with increased plasma levels of 12alpha-hydroxylated bile acids. Diabetes 2013;62(12):4184-91.

[36] Sachdev S, Wang Q, Billington C, Connett J, Ahmed L, Inabnet W, et al. FGF 19 and bile acids increase following roux-en-y gastric bypass but not after medical management in patients with type 2 diabetes. Obes Surg 2016;26 (5):957-65.

37] Proano M, Camilleri M, Phillips SF, Brown ML, Thomforde GM. Transit of solids through the human colon: regional quantification in the unprepared bowel. Am J Physiol 1990;258(6 Pt 1):G856-62.

[38] Cremonini F, Mullan B, Camilleri M, Burton D, Rank M. Performance characteristics of scintigraphic transit measurements for studies of experimental therapies. Aliment Pharmacol Ther 2002;16(10):1781-90

[39] Odunsi-Shiyanbade ST, Camilleri M, McKinzie S, Burton D, Carlson P, Busciglio IA et al. Effects of chenodeoxycholate and a bile acid sequestrant, colesevelam, on intestinal transit and bowel function. Clin Gastroenterol Hepatol 2010;8(2): 159-65.

[40] Malmstrom H, Walldius G, Grill V, Jungner I, Gudbjornsdottir S, Hammar N. Fructosamine is a useful indicator of hyperglycaemia and glucose control in clinical and epidemiological studies-cross-sectional and longitudinal experience from the Amoris cohort. PLoS ONE 2014;9(10):e111463.

[41] Ma K, Saha PK, Chan L, Moore DD. Farnesoid x receptor is essential for normal glucose homeostasis. J Clin Invest 2006;116(4):1102-9.

[42] Bonde Y, Eggertsen G, Rudling M. Mice abundant in muricholic bile acids show resistance to dietary induced steatosis, weight gain, and to impaired glucose metabolism. PLoS ONE 2016:11(1):e0147772.

[43] Rudling M. Understanding mouse bile acid formation: is it time to unwind why mice and rats make unique bile acids? J Lipid Res 2016;57(12):2097-8.

[44] de Bruine AP, Dinjens WN, Pijls MM, vd Linden EP, Rousch MJ, Moerkerk PT, et al. $\mathrm{NCI}-\mathrm{H} 716$ cells as a model for endocrine differentiation in colorectal cancer Virchows Arch B Cell Pathol Incl Mol Pathol 1992;62(5):311-20.

[45] Kuhre RE, Wewer Albrechtsen NJ, Deacon CF, Balk-Moller E, Rehfeld JF, Reimann F, et al. Peptide production and secretion in GLUTag, NCI-H716, and STC-1 cells: a comparison to native L-cells. J Mol Endocrinol 2016;56(3):201-11.

[46] Valentin N, Camilleri M, Altayar O, Vijayvargiya P, Acosta A, Nelson AD, et al. Biomarkers for bile acid diarrhoea in functional bowel disorder with diarrhoea: a systematic review and meta-analysis. Gut 2016;65(12):1951-9.

[47] Keely SJ, Walters JR. The farnesoid X receptor: good for bad. Cell Mol Gastroenterol Hepatol 2016;2(6):725-32.

[48] Kliewer SA, Mangelsdorf DJ. Bile acids as hormones: the FXR-FGF15/19 pathway. Dig Dis 2015;33(3):327-31.

[49] Wojcik M, Janus D, Dolezal-Oltarzewska K, Kalicka-Kasperczyk A, Poplawska K, Drozdz D, et al. A decrease in fasting FGF19 levels is associated with the development of non-alcoholic fatty liver disease in obese adolescents. J Pediatr Endocrinol Metab 2012;25(11-12):1089-93.

[50] Gomez-Ambrosi J, Gallego-Escuredo JM, Catalan V, Rodriguez A, Domingo P, Moncada R, et al. FGF19 and FGF21 serum concentrations in human obesity and type 2 diabetes behave differently after diet- or surgically-induced weight loss. Clin Nutr 2017;36(3):861-8

[51] Gallego-Escuredo JM, Gomez-Ambrosi J, Catalan V, Domingo P, Giralt M, Fruhbeck G, et al. Opposite alterations in FGF21 and FGF19 levels and disturbed expression of the receptor machinery for endocrine FGFs in obese patients. Int J Obes (Lond) 2015;39(1):121-9.

[52] Mannucci E, Ognibene A, Cremasco F, Bardini G, Mencucci A, Pierazzuoli E, et al Glucagon-like peptide (GLP)-1 and leptin concentrations in obese patients with type 2 diabetes mellitus. Diabet Med 2000;17(10):713-9.

[53] Vilsboll T, Krarup T, Deacon CF, Madsbad S, Holst JJ. Reduced postprandial concentrations of intact biologically active glucagon-like peptide 1 in type 2 diabetic patients. Diabetes 2001;50(3):609-13.

[54] Batterham RL, Cohen MA, Ellis SM, Le Roux CW, Withers DJ, Frost GS, et al. Inhibition of food intake in obese subjects by peptide YY3-36. N Engl J Med 2003;349 (10):941-8.

[55] Gribble FM, Meek CL, Reimann F. Targeted intestinal delivery of incretin secretagogues-towards new diabetes and obesity therapies. Peptides 2018;100: $68-74$

[56] Camilleri M, Iturrino J, Bharucha A, Burton D, Shin A, Jeong ID, et al. Performance characteristics of scintigraphic measurement of gastric emptying of solids in healthy participants. Neurogastroenterol Motil 2012;24(12):1076. the official journal of the European Gastrointestinal Motility Society.

[57] Pedersen O, Nielsen O, Bak J, Richelsen B, Beck-Nielsen H, Sorensen N. The effects of metformin on adipocyte insulin action and metabolic control in obese subjects with type 2 diabetes. Diabet Med 1989;6(3):249-56.

[58] Evans JL, Heymann CJ, Goldfine ID, Gavin LA. Pharmacokinetics, tolerability, and fructosamine-lowering effect of a novel, controlled-release formulation of alphalipoic acid. Endocr Pract 2002;8(1):29-35.

[59] Cefalu WT, Schneider DJ, Carlson HE, Migdal P, Gan Lim L, Izon MP, et al. Effect of combination glipizide GITS/metformin on fibrinolytic and metabolic parameters in poorly controlled type 2 diabetic subjects. Diabetes Care 2002;25(12): 2123-8.

[60] Bronden A, Alber A, Rohde U, Gasbjerg LS, Rehfeld JF, Holst JJ, et al. The bile acidsequestering resin sevelamer eliminates the acute GLP-1 stimulatory effect of 
endogenously released bile acids in patients with type 2 diabetes. Diabetes Obesity Metabolism 2018;20(2):362-9.

[61] Potthoff MJ, Potts A, He T, Duarte JA, Taussig R, Mangelsdorf DJ, et al. Colesevelam suppresses hepatic glycogenolysis by TGR5-mediated induction of GLP-1 action in DIO mice. Am J Physiol Gastrointest Liver Physiol 2013;304(4):G371-80.
[62] Shang Q, Saumoy M, Holst JJ, Salen G, Xu G. Colesevelam improves insulin resistance in a diet-induced obesity (F-DIO) rat model by increasing the release of GLP-1. Am J Physiol Gastrointest Liver Physiol 2010;298(3):G419-24.

[63] Sun L, Xie C, Wang G, Wu Y, Wu Q, Wang X, et al. Gut microbiota and intestinal FXR mediate the clinical benefits of metformin. Nat Med 2018;24(12):1919-29. 